\title{
Oral and Cutaneous Melanoma: Similarities and Differences
}

\author{
Rafaela Nogueira Moreira ${ }^{a}$, Cassio Roberto Rocha Santos ${ }^{\mathrm{b}}$, Nadia Lages Lima ${ }^{\mathrm{b}}$, \\ Flaviana Dornela Verlib, Sandra Aparecida Marinho ${ }^{\mathrm{b}, \mathrm{c}}$
}

\begin{abstract}
Melanomas are malignant lesions stemming from the disorganized proliferation of melanocytes. This condition is more common on skin, but may also be detected in mucosa, such as in the oral cavity. The aim of the present study was to report similarities and differences between oral and cutaneous melanoma.
\end{abstract}

Keywords: Melanoma; Skin; Mouth; Diagnosis

\section{Introduction}

Melanoma originates from the malignant transformation of melanocytes [1]. Oral melanoma is not as common as cutaneous melanoma and has the worst prognosis among malignant tumors $[2,3]$. Due to the greater tendency toward metastasis, oral melanoma is considered quite aggressive [4, 5]. Early diagnosis is therefore important [6]. Fortunately, both the oral cavity and skin is of easy access to exams, which may increase the chances of survival [7]. Early diagnosis and treatment are essential for a better prognosis regarding melanomas and reduced risk of mortality [8-10].

As oral melanoma may be asymptomatic in the early stages, it is often only perceived after the appearance of symptoms such as pain, bleeding and ulceration [9]. Most

\footnotetext{
Manuscript accepted for publication July 15, 2010

${ }^{\text {a }}$ Postgraduate Program in Dentistry, Federal University of the Jequitinhonha and Mucuri Valleys (UFVJM), Diamantina, Minas Gerais, Brazil

${ }^{\mathrm{b}}$ Postgraduate Program in Dentistry, Pathology Laboratory, Federal University of the Jequitinhonha and Mucuri Valleys (UFVJM), Diamantina, Minas Gerais, Brazil

cCorresponding author, Email: san_mar2000@yahoo.com.br
}

doi:10.4021/jocmr416w cases of oral melanoma (66.6\%) were diagnosed in advanced stages, with lesions greater than $4 \mathrm{~cm}$ in diameter; distant metastases were encountered, especially in the lungs; and mean survival was 16.9 months, with only $6.6 \%$ of patients surviving more than five years [11].

The aim of the present study was to report the similarities and differences between oral and cutaneous melanoma.

\section{Review and Discussion}

According to Rivers [12] (1996), a single melanoma occurs only occasionally. However, two lesions, with one as a satellite to the main lesion, are relatively common [9]. This occurs due to embolic propagation to the lymph vessels, with the development of secondary tumors a short distance from the primary tumor [13].

Oral melanomas are more commonly found in the maxilla, especially in the palate and gums $[1,4-6,14-16]$. The mandible is only involved in $20 \%$ of cases [5, 17]. The preferential location of melanoma in the head and neck is the nasal cavity, which may explain why oral melanoma is more common in the palate, considering the proximity and embryological origin. As these two structures are continually exposed to inhaled air, it is possible that irritants and carcinogenic compounds in the air, such as the components of cigarette smoke, play a contributing role in the development of lesions in these sites [2]. However, the relative role of toxic substances, medications and hormones, such as during pregnancy and the use of hormonal contraceptives, remains unclear. Immune status also plays a determinant role in the course of melanoma, considering its rapid progression in immunosuppressed individuals [18].

Unlike cutaneous melanoma, the pathogenesis and etiogenesis of mucosal melanoma are not yet clear or defined $[1,8,15,17,19]$. Sun exposure is not related to the etiology of oral melanoma, but is clearly linked to cutaneous melanoma. Factors such as family history, syndromes, cytogenetic defects, growth factors, pre-existing lesions, mechanical trauma, denture use, infection, oral habits, self-medication, eating disorders, smoking habits and exposure to formaldehyde and other carcinogenic substances may have some etio- 
logical significance $[5,20]$. Racial, cultural and geographic factors may also predispose individuals to the disease [20]. Japanese, African, American and Hispanic individuals are more commonly affected by oral melanoma, with a greater predilection for the male gender $[1,5,21,22]$. However, Pour et al [6] (2009) reported a greater prevalence of oral melanoma among women.

The genetic theory regarding the cause of the malignant transformation of pigmented benign tumors is founded on the expression of certain antigens during the transformation process of the benign melanocytic nevus to melanoma, with an alteration in the p53 protein identified in two-thirds of cases. Cytogenetic analysis of a specific gene in melanocytes seems to be very useful to the understanding of the pathogenesis [19]. According to Tanaka et al [23] (2001), the biological behavior of melanoma may be associated to the expression of the proteins $\mathrm{Rb}, \mathrm{pRb} 2 / \mathrm{p} 130, \mathrm{p} 53$ and $\mathrm{p} 16$, which may be useful in predicting the appearance of this neoplasm.

Melanoma may present as either a flat or nodular, painless, dark brown or black lesion with erythema, ulceration and bleeding $[8,21]$. The invasion of the conjunctive tissue with atypical melanocytes alters the configuration of the surface of the lesion. Initially, macular melanoma develops in situ and may later become nodular [24]. Gorsky et al [2] (1998) found that oral lesions were more often diagnosed as nodules, with only $40 \%$ of patients complaining of pain or discomfort. In the clinical aspect, the majority of such lesions are described as non-pigmented. Bone erosion is common as the disease progresses $[4,21]$. Deep extension, with or without bone invasion, is present in the diagnosis of many cases. However, surface dissemination prior to vertical dissemination is possible and one third of patients with oral melanoma exhibit previous benign melanin pigmentation [25].

An important issue in the management of oral melanoma is to exclude the possibility of its being a metastasis of a cutaneous melanoma, which would affect the determination of the treatment [21]. Greene et al [26] (1953) proposed three useful criteria in the diagnosis of primary oral melanoma: the presence of malignant melanoma in the oral mucosa; the exclusion of melanoma in any other primary site; and the histopathological determination of junction activity, which is described as melanocytes arranged throughout the basal layer of the surface epithelium.

The Clark and Breslow classifications are the most often used assessment systems for the prognosis of cutaneous melanoma [27, 28]. While the Clark classification assesses the depth of the invasion, the Breslow measurement system analyzes the thickness of the tumor of greatest depth to the beginning of the granular layer. These two classification systems have not been validated as prognostic predictors of oral melanoma, likely due to the rarity of this lesion. Moreover, unlike cutaneous melanoma, more oral melanomas are larger than $4 \mathrm{~mm}$ upon initial presentation [6].

Prasad et al [29] (2004) established a three-level micro- stage system: Level I - in situ melanoma either with no evidence of invasion or with the presence of individual or agglomerated invasive melanocytes with less than 10 atypical melanocytes near the subethelial junction; Level II - melanoma cells limited to the lamina propria; and Level III - invasion of the deep conjunctive tissue, including skeletal muscle, bone or cartilage. Barker et al [30] (1997) presented a variation of the histological classification: in situ melanoma, restricted to the epithelium; invasive melanoma, extending to the connective tissue; and mixed melanoma, which is a combination of the in situ and invasive forms.

A number of factors may contribute toward a poor prognosis for oral melanoma, including the absence of symptoms in the early stage of the disease and difficulty determining the width of the radial excision due to anatomic limitations and rich blood supply to the region, which may facilitate hematogenic propagation $[4,7,15,19,21,22,25]$. Lymph nodes, lungs, liver and brain are common sites of metastasis and are often involved in advanced stages of the disease [7, 8].

The five-year survival rate for oral melanoma is generally only between $10 \%$ and $25 \%$ due to the late detection stemming from the fact that this lesion is less visible than cutaneous melanoma [10]. Lymphatic metastasis at the time of diagnosis seems to be the most important prognostic factor for oral melanoma [8]. Early diagnosis and treatment can reduce the chances of mortality. If diagnosed early enough, when the malignant cells are limited to the epidermis or when there is minimal invasion, melanoma is $100 \%$ curable through surgery or is associated to a $95 \%$ five-year survival rate for lesions under $1 \mathrm{~mm}$ in thickness without ulceration. In contrast, the five-year survival rate for cutaneous melanoma with lesions larger than $4 \mathrm{~mm}$ in thickness and ulceration is only $45 \%$ [31].

Unlike with cutaneous melanoma, excision biopsy is not feasible for oral melanoma due to the presence of teeth and bone in the region [15]. Aggressive resection with the complete removal of the tumor is also hindered for this reason and incomplete resection contributes toward recurrence or metastasis [4].

As with the cutaneous form, oral melanoma can usually be diagnosed with hematoxylin-eosin staining, which allows easy identification of the disease through its junction activity, diffuse arrangement of spherical or spiny cells with abundant eosinophilic cytoplasm marked by cellular atypia, eosinophilic nucleolus and abundant mitotic figures [32]. However, if the lesion is completely devoid of pigment and the clinical hypothesis of melanoma is not posed, immunohistochemical analysis using the protein markers S-100, gp-100, HMB-45 and mart-1 is useful [10, 32]. Amelonotic melanoma is rare and has a worse prognosis in comparison to pigmented lesions due to the delayed establishment of the correct diagnosis and onset of treatment $[6,7]$.

Surgery is the most indicated form of treatment for mel- 
anoma. Depending on the stage, chemotherapy and radiotherapy may be used as adjuvant treatment. However, when there is metastasis, melanoma is incurable in most cases $[9,11,13]$. Radiotherapy may be used as a complementary treatment following surgery or when previous treatment has failed [2]. Radiotherapy may also be used as the only treatment in elderly patients or in the preoperative phase for the reduction of the tumor and alleviation of pain symptoms in cases of bone metastasis [13]. Umeda and Shimada [33] (1994) adopted a protocol that consists of surgery of the lesion through oral access, with a $1.5 \mathrm{~cm}$ margin of safety, excision of any lymph node with regional metastasis and the administration of chemotherapy. According to Smith et al [13] (1993), a 1 cm margin is likely adequate for tumors of the oral cavity and a combination of treatments may provide greater benefits to the patient.

Experimental studies carried out on mice and in vitro have demonstrated that hollow nanoparticles made of gold aggregated to peptides have an affinity for the receptors of melanoma cells and penetrate these cells. Following injection into the organism and an infrared light bath, the cancer cells with nanoparticles in their interior are destroyed by photothermal damage, with the loss of the cell membrane and protein denaturation. This treatment is known as plasmonic photothermal therapy [34]. Gene therapy with the use of modified melanoma cells containing specific genes that code for cytokines, interferon and growth factors may be administered, such as tumor cell vaccines [12]. Immunotherapy may also be incorporated to melanoma treatment, although patient immune response may be significantly altered by the clinical course of the neoplasm [35]. Interleukin-2, interferon alpha, tumor-infiltrating lymphocytes, bacillus CalmetteGuerin, irradiated allogeneic tumor cells and monoclonal antibodies can be used [36].

Preoperative investigations, such as chest x-ray, kidney function test and abdominal ultrasound, should be performed for the identification of metastasis. In the determination of bone metastasis, computed tomography reveals the extent of invasion into structures adjacent to the mouth, such as the nasal cavity or eye, and a possible recurrence of metastasis in regional lymph nodes. When there is distant metastasis due to hematogenic propagation, aggressive surgery is not indicated and either only local palliative excision or no surgery is recommended. Regional metastasis is uncommon, but, when it occurs, there is local recurrence and distant metastasis in the majority of cases [13]. For melanomas greater than $1 \mathrm{~mm}$ in thickness, ultrasonography of the lymph nodes and abdomen (including the pelvis and retroperitoneum) are indicated. The first five years following surgery are the most important, with $90 \%$ of all cases of metastasis occurring in this period [18].

Health care professionals should be attentive to pigmented lesions in the mucosa as well as skin, carrying out detailed, discerning exams. Mucosal melanoma, especially in the oral cavity, is rare, but is more aggressive and has a poorer prognosis. Nonetheless, if diagnosed early, complete cure is possible.

\section{Conflict of Interests}

There is no conflict of interests.

\section{References}

1. Jahanbani J, Forouzandeh A, Sadri D, Mirlashari J. Oral malignant melanoma diagnosed in an Iranian population over an 11-year period. Oral Maxillofac Surg 2008;12(4):181-183.

2. Gorsky M, Epstein JB. Melanoma arising from the mucosal surfaces of the head and neck. Oral Surg Oral Med Oral Pathol Oral Radiol Endod 1998;86(6):715-719.

3. Kalkman E, Baxter G. Melanoma. Clin Radiol 2004;59(4):313-326.

4. Gu GM, Epstein JB, Morton TH, Jr. Intraoral melanoma: long-term follow-up and implication for dental clinicians. A case report and literature review. Oral Surg Oral Med Oral Pathol Oral Radiol Endod 2003;96(4):404413.

5. Aguas SC, Quarracino MC, Lence AN, LanfranchiTizeira HE. Primary melanoma of the oral cavity: ten cases and review of 177 cases from literature. Med Oral Patol Oral Cir Bucal 2009;14(6):E265-271.

6. Pour MSH. Malignant melanoma of the oral cavity. J of Dentistry. Tehran University of Medical Sciences 2007;4:44-51.

7. Symvoulakis EK, Kyrmizakis DE, Drivas EI, Koutsopoulos AV, Malandrakis SG, Skoulakis CE, Bizakis JG. Oral mucosal melanoma: a malignant trap. Head Face Med 2006;2(7.

8. Ardekian L, Rosen DJ, Peled M, Rachmiel A, Machtei EE, el Naaj IA, Laufer D. Primary gingival malignant melanoma. Report of 3 cases. J Periodontol 2000;71(1):117-120.

9. Ebenezer J. Malignant melanoma of the oral cavity. Indian J Dent Res 2006;17(2):94-96.

10. Auluck A, Zhang L, Desai R, Rosin MP. Primary malignant melanoma of maxillary gingiva--a case report and review of the literature. J Can Dent Assoc 2008;74(4):367-371.

11. Lopez-Graniel CM, Ochoa-Carrillo FJ, Meneses-Garcia A. Malignant melanoma of the oral cavity: diagnosis and treatment experience in a Mexican population. Oral Oncol 1999;35(4):425-430.

12. Rivers JK. Melanoma. Lancet 1996;347(9004):803-806.

13. Smyth AG, Ward-Booth RP, Avery BS, To EW. Malignant melanoma of the oral cavity--an increasing clinical 
diagnosis? Br J Oral Maxillofac Surg 1993;31(4):230235 .

14. D'Silva NJ, Kurago Z, Polverini PJ, Hanks CT, Paulino AF. Malignant melanoma of the oral mucosa in a 17-year-old adolescent girl. Arch Pathol Lab Med 2002;126(9):1110-1113.

15. van der Waal R, van der Waal I. Oral non-squamous malignant tumors; diagnosis and treatment. Med Oral Patol Oral Cir Bucal 2007;12(7):E486-491.

16. Pour MAH, Rad M, Zare MR, Chamani G. Malignant melanoma of the head and neck in an Iranian population over an 11-year period. Am J applied Sci 2009;6:14671472.

17. Perrotti V, Piattelli A, Rubini C, Fioroni M, Petrone G. Malignant melanoma of the maxillary gingiva: a case report. J Periodontol 2004;75(12):1724-1727.

18. Garbe C, Hauschild A, Volkenandt M, Schadendorf D, Stolz W, Reinhold U, Kortmann RD, et al. Evidence and interdisciplinary consense-based German guidelines: diagnosis and surveillance of melanoma. Melanoma Res 2007;17(6):393-399.

19. Meleti M, Leemans CR, Mooi WJ, Vescovi P, van der Waal I. Oral malignant melanoma: a review of the literature. Oral Oncol 2007;43(2):116-121.

20. Desmond RA, Soong SJ. Epidemiology of malignant melanoma. Surg Clin North Am 2003;83(1):1-29.

21. Chiu TT, Lin HC, Su CY, Huang CC. Primary malignant melanoma of the tongue. Chang Gung Med J 2002;25(11):764-768.

22. White N, Yap LH, Srivastava S. Lymphadenectomy for melanoma in the clinically N1 neck: radical, modified radical, or selective? J Craniofac Surg 2009;20(2):385388.

23. Tanaka N, Odajima T, Mimura M, Ogi K, Dehari H, Kimijima Y, Kohama G. Expression of Rb, pRb2/p130, $\mathrm{p} 53$, and p16 proteins in malignant melanoma of oral mucosa. Oral Oncol 2001;37(3):308-314.

24. Friedman RJ, Heilman ER. The pathology of malignant melanoma. Dermatol Clin 2002;20(4):659-676.

25. Gonzalez-Garcia R, Naval-Gias L, Martos PL, NamCha SH, Rodriguez-Campo FJ, Munoz-Guerra MF, Sastre-Perez J. Melanoma of the oral mucosa. Clinical cases and review of the literature. Med Oral Patol Oral
Cir Bucal 2005;10(3):264-271.

26. Greene GW, Haynes JW, Dozier M, Blumberg JM, Bernier JL. Primary malignant melanoma of the oral mucosa. Oral Surg Oral Med Oral Pathol 1953;6(12):14351443.

27. Clark WH, Jr., From L, Bernardino EA, Mihm MC. The histogenesis and biologic behavior of primary human malignant melanomas of the skin. Cancer Res 1969;29(3):705-727.

28. Breslow A. Thickness, cross-sectional areas and depth of invasion in the prognosis of cutaneous melanoma. Ann Surg 1970;172(5):902-908.

29. Prasad ML, Patel SG, Huvos AG, Shah JP, Busam KJ. Primary mucosal melanoma of the head and neck: a proposal for microstaging localized, Stage I (lymph nodenegative) tumors. Cancer 2004;100(8):1657-1664.

30. Barker BF, Carpenter WM, Daniels TE, Kahn MA, Leider AS, Lozada-Nur F, Lynch DP, et al. Oral mucosal melanomas: the WESTOP Banff workshop proceedings. Western Society of Teachers of Oral Pathology. Oral Surg Oral Med Oral Pathol Oral Radiol Endod 1997;83(6):672-679.

31. Doval DC, Rao CR, Saitha KS, Vigayakumar M, Misra S, Mani K, Bapsy PP, et al. Magliant melanoma of the oral cavity: report of 14 cases from a regional cancer centre. Eur J Surg Oncol 1996;22(3):245-249.

32. Pour MAH, Rad M, Zare MR, Chamani G. Malignant melanoma of the head and neck in an Iranian population over an 11-year period. Am J applied Sci 2009;6:14671472.

33. Umeda M, Shimada K. Primary malignant melanoma of the oral cavity--its histological classification and treatment. Br J Oral Maxillofac Surg 1994;32(1):39-47.

34. Huang X, Jain PK, El-Sayed IH, El-Sayed MA. Plasmonic photothermal therapy (PPTT) using gold nanoparticles. Lasers Med Sci 2008;23(3):217-228.

35. Nakahara H, Kitamura R, Shirasuna K. Simultaneous malignant melanoma and squamous cell carcinoma of the oral cavity: a case report. J Oral Maxillofac Surg 1995;53(12):1455-1457.

36. Patton LL, Brahim JS, Baker AR. Metastatic malignant melanoma of the oral cavity. A retrospective study. Oral Surg Oral Med Oral Pathol 1994;78(1):51-56. 